William J. Samarin

\title{
LINGUA FRANCAS OF THE WORLD
}

\section{ORIGIN OF THE TERM}

The language of the Crusaders was not the first lingua franca in the history of mankind, but it furnished the name for all such similar languages ever since.

The horde which descended upon the Muslims on the eastern shores of the Mediterranean had come from many parts of western Europe. The native languages (the vernaculars) of these priests and soldiers, merchants and blacksmiths, porters and page boys, were forerunners of English, French, Italian, and German. Though Latin was the language of religion and of learning, the Crusaders did not all speak Latin, nor did they speak each other's languages. While there were certainly bilinguals among them, there were with equal certainty people who did not understand even other dialects of their own language: an Englishman from the South might find it difficult if not impossible to understand an Englishman from the North on the first encounter.

Linguistic diversity (i.e., multilingualism) has always set the stage for the development of lingua francas, and the multilingual Crusaders thrown together for a common cause found a need for such a language. They found it in the language of Provençal, spoken along the southern shores of Europe between Marseilles and Genoa. Perhaps this "French language" (which is what lingua franca literally means, though it was rost likely only a particular dialect of a Romance language) had already come to be used by native and foreign merchants and sailors whose business was in these southern ports. In any case, it became the basis of a language used among the Crusaders and with the non-French speaking peoples who had learned it. 
The use of this particular form of French eventually died out, but not before having left its own name as its heritage for languages which are used in a similar fashion. Today when we find a language which is commonly used by people whose native languages are different, we describe it as a lingua franca.

\section{A DEFINITION}

If the term lingua franca is to be used with the widest possible meaning it is necessary to adopt a definition with the fewest restrictions. The following (UNESCO 1953, p. 46) is worthy of general adoption: "A language which is used habitually by people whose mother tongues are different in order to facilitate communication between them." An additional requirement included in some definitions is that a lingua franca be a pidgin language (a so-called "hybrid" or "mixed" language), but it is not true that all lingua francas are pidgins. A second requirement sometimes found is that a lingua franca be used for commercial purposes, but this is again not always true of lingua francas, though they frequently arise in a commercial environment.

Other terms compete with lingua franca as designations for the kind of language being discussed.

Trade language ("langue de traité") is usually used for some language not included among the world's majority languages and which is used by some people as a second language in commercial situations. All trade languages are therefore lingua francas, e.g., Kituba and Hausa in Africa.

Contact language (probably equivalent to French "langue véhiculaire") is a lingua franca whose use is not necessarily habitual. It is the most neutral of the terms.

International (or Universal) language is a lingua franca whose use is actually or virtually international. Some writers, however, make the error of using it of lingua francas indiscriminately, even of those with restricted use, e.g., English, French.

Auxiliary language is generally meant to describe an artificially devised lingua franca, e.g., Esperanto.

\section{KINDS OF LINGUA FRANCAS}

Since a lingua franca is simply a language used to communicate across linguistic barriers, it can itself be any kind of a language; natural, pidginized, or planned. By natural language is meant any language acquired by the normal processes of inculturation. Natural languages are 
thus the mother or native languages of some people. When a natural language is acquired as the second language of different people, it becomes their lingua franca. In the process of becoming a lingua franca, a language often loses some of its vocabulary or is simplified in its phonology or grammar. Where the structure of the language suffers serious modification, it is said to be pidginized.

A pidginized language, or simply pidgin, traces its lineage to at least one natural language. A pidgin, strictly speaking, is not a natural language (sce above). However, it may become a natural language; at this point it may be called a creole (Hall, 1962).

Unlike either of the preceding kinds of lingua francas are the planned languages. Not all such languages are lingua francas, of course, for some are intended for very restricted use. All such languages were created ad hoc, though based on some natural languages, for express use as lingua francas.

\section{NATURAL LANGUAGE LINGUA FRANCAS}

Three natural language lingua francas have played an important role in the history of Western Civilization: Common Greek (Koiné), Latin, and French (Goad 1958).

For almost 800 years ( 300 B.C. to 500 A.D.) the civilized part of the Mediterranean world was unified by the Greek lingua franca. At almost every level of society, irrespective of circumstances, this language was used. Like so many lingua francas, Common Greek owes its origin to military conquest. Although the culture of the city states attracted admiration and emulation, it was not until the establishment of Alexander's empire that the language became strategic. A single empire needs one universal language.

Koiné, however, far outlived the empire. At no period after Alexander's death was there the unity and prosperity characteristic of his dynamic era. Yet for several hundred more years - even after the Romans assumed political hegemony - Greek was used by tradesmen and scholars alike. It was, however, only in the last century that we learned how widely Koiné was actually used among ordinary people. With the discovery of the papyri was revealed the unsophisticated use of the lingua franca in everyday affairs. They were written not only by Greeks but also by Egyptians, Persians, and Arabs alike. Before the discovery of the papyri, our best knowledge of the Koine was in the Greek translation of the Hebrew Scriptures (the Septuagint version of the Old Testament), and in the Christian writings (the New Testament).

The Greek lingua franca did more than spread Greek culture. In a 
very real sense, it served to spread the religion with which western civilization ever since has been identified - Christianity. Had there not been such a contact language, it seems hardly possible that the propagators of the new religion would have found an audience. But in Palestine, Asia Minor, and perhaps even the Iberian peninsula, St. Paul found important groups of people whom he addressed in Greek. Like the early Christian leaders, the so-called Patristic fathers also wrote in Greek. The language of the Church for all practical purposes was Greek.

At this time, of course, Rome ruled the Mediterranean. But Latin was hardly competition for Koiné. While it is true that Latin literature reached its apogee in the works of such artists as Plautus, Virgil, Livy, or Cicero, the classic language itself seems to have been more a written than spoken one. While orations may have been delivered in the Senate in this literary language - or even Greek - it was the "vulgar" language which was used elsewhere.

Latin later became another lingua franca, identified not so much with a political institution as with a religious one. The Roman Church had continued to use it even after the fall of Rome, and out of the ruins of that civilization the Church arose, adopting a form of the spoken Latin. Its clergy learned and used this language. Political leaders like Charlemagne, by encouraging learning, encouraged its study. Western Europe was not united under one crown, but under one miter. Germans, Scandinavians, Saxons, and North Africans could carry on business and pursue scholarly activities. Until the 16th century, deeds and documents worthy of preservation were in Latin. So commonly do we think today of the English translations of the writings of the savants of the past, whether religious (like Augustine's) or not (like Bacon's and Sir Thomas More's), that we forget that these were first in Latin.

With the maturation of the Renaissance, the vernaculars began to play a greater part in the politics and art of the West. Wycliffe strove for an English translation of the Bible. Dante used the Italic dialect of Tuscany for his masterpieces. Treaties began to be written in other languages than Latin. By the 18th century, French had already become the West's new lingua franca. But it was a different kind of lingua franca, less plebeian by far than Koiné, and less regnant than Latin. A literary lingua franca, less widely known than its forerunner.

In other parts of the world too lingua francas have been or are now used by millions of people. The more important ones are here classified by language families.

Afro-Asiatic (a name proposed by Joseph $\mathrm{H}$. Greenberg to include the Semitic and related languages of Africa). Between the fifth century B.C. and the fourth century A.D. Aramaic was used in Babylonia, Palestine, Syria, and Egypt. Later Arabic served as a lingua franca in 
some places following the Muslim conquests. Hausa, a Chadic language, serves as a trade language in Dahomey, Togo, Ghana, Upper Volta, Nigeria, and the Cameroon by several millions.

Chinese. Among the several important Chinese languages, Mandarin first became the lingua franca of education and government and then became the standard language, which by official policy is replacing local languages as on Taiwan.

Hindi. The national language of India is derived from a language of the same name spoken in the northeastern part of the Republic. Soon after the Muslim conquest of the 12th century, this language began to be used as a lingua franca of the courts, army camps, and trading centers.

Niger-Congo. In Africa several languages belonging to this family have served or are serving now as lingua francas, such as Bambara and Fulani in the West, and Ngbandi in northern Congo. Swahili and Lingala can also be included here, but because they are also commonly used in pidginized form are later classified among the pidgins.

\section{PLANNED-LINGUA FRANCAS}

Several planned-language linguage francas have been devised within the last seventy-five years. They are Esperanto, which claims 1,500,000 speakers, Ido, similar to Esperanto, Novial, Frater, and three others which compete for the name Interlingua (Ferguson, n.d.). More recently Loglan came into being. Designed by scientists, its chief claim is to simplicity and logicality.

The advocates of each planned language appear to be as loyal to their tongue as nationalists are to theirs. Dispassionate appraisals and linguistic evaluations of these languages are therefore rare.

Planned languages reveal many of the features of pidgin languages, namely, lexical syncretism and reduction of redundancy. Frater, for example, is based on Latin and Greek roots which purport to have international utility. Thus, mutalingua is "translation", akusa is "accuse", ani is "one". As for redundancy, "In Frater, there is neither article, nor flexion, nor elision, nor affix, nor concord of tense, of mood, of gender, of number." ( Thai, 1957).

\section{PIDGIN LANGUAGES}

Pidgin languages as a group typify most completely the lingua francas in their development and structure. Bona fide pidgins are found all over the world and have been under observation for about one hundred years. However, it was not until recently that they have been submitted to careful analysis. The reason for this was the opinion that pidgins at 
their best were nothing more than poor approximations to cultural languages such as English and French.

What people failed to see was that these forms of speech were not "hodge-podge" mixtures of linguistic debris, but that in every case studied there was genuine linguistic structure. The earliest of such studies was Hall's of Melanesian Pidgin English (Hall, 1945).

The bibliography reveals that today many scholars are working on several different pidgins. The published literature has not only made available working data on the languages, but has also raised several interesting theoretical or methodological questions, such as the following: (1) Can pidgins be classified as belonging to language families like natural languages? (2) What are the psychologicai and social correlates of their use? (3) Can they be described with the same rigor as natural languages?

The list of pidgin languages is an imposing one. The following may possibly be a complete one for the last century.

African pidgins (Niger-Congo languages)

Bangala-Lingala: spoken in the Congo and derived from Ngala; Bangala is supposed to be the more simplified of the two.

Pidgin A70 (also known as Chauffeur Bulu, Bulu bediliva, Ewondo Populaire): spoken in the Cameroon, derived from the group of Bantu languages designated A70 (Alexandre).

Fanagalo (also known as Fanikalo, Chilapalapa, Kitchen or Mine Kafir, Isikula, Cikabanga, Cilololo, Cilungubo, "Basic Bantu"): a pidgin Zulu of Southeast Africa.

Kituba (also known as Commercial Kikongo, from which it is derived, Simple Kikongo, Kibulamatadi, Kikwango): spoken in the Congo.

Sango: derived from a language of the same name which is an intimate dialect with Ngbandi; spoken in the Central African Republic.

Swahili: derived from the language of the same name; spoken in Tanganyika and neighboring areas; the dialect of the Eastern Congo is called Kingwana.

As linguistic curios a few others might be cited: Coromanti (spoken in Jamaica around 1800, and derived from some West African language, Le Page 1960, p. 98); Nago, probably based on Yoruba and ultimately used only in certain Brazilian pseudo-African cults (Pierson 1942, p. 73).

\section{Amerindian pidgins}

Chinook Jargon: spoken in the American Northwest and neighboring part of Canada.

Island Carib (or "men's speech" Karina) can possibly be included here. 
Chinese: spoken along the northwestern border of Indo-China (Whinnom 1956, p. viii).

\section{English}

Cameroon

Chinese

Hawaiian

Jamaican (and perhaps other Caribbean pidgins, excluding the last two)

Korean Bamboo English

Melanesian

Sierra Leone

Saramakan (Jew Tongo, Ningre-Tongo)

Sranan

\section{French}

Caribbean (Haiti, Louisian, Martinique)

Indian Ocean (Seychelles, Mauritius Islands)

Vietnam (?)

\section{Portuguese}

African (San Thomé, Principe, Cap Verde)

Caribbean (Papiamento)

Far East (Cochin, Malaya, etc.)

Spanish (in the Philippines)

Bamboo Spanish

Caviteño

Davaueño

Ermitaño

Ternateño

Zambangueño

If a pidgin language is used long enough in any one area, children reared in this community acquire it as their native language. When this happens the pidgin becomes the natural language of a segment of the population and is said to be creolized. This creolized language may outlive the competing languages or it may simply become fully naturalized. At this point it is said to be a creole (while the process here described is well known, the terminology may not represent a consensus; writers differ in the technical use of the word "creole").

The list of pidgin lingua francas scattered throughout the world hides an important fact. Though numerous and widespread, most of them are based on some Indo-European language - Dutch, English, French, 
Portuguese, or Spanish. When located on a map, another significant fact appears, every one is located adjacent to a marine expanse. The history of these pidgins is therefore somehow to be connected with oceanic travel. This is, in fact, the case. What is not obvious, however, but certainly demonstrable, is the fact that a remarkable number of these lingua francas owe their origin to the heroic masters of the Age of Exploration, the Portuguese. In the fifteenth century there developed a pidgin Portuguese which may have originated in the first contacts with the Africans, but ultimately spread to the ports of the Far East (Lopes da Silva). According to Whinnom, "Even at the beginning of the eighteenth century, English trade at Canton was carried on through Eurasian Portuguese interpreters who translated the Cantonese into a Portuguese pidgin comprehensible to the English sailors (Whinnom, p. 7, fn. 13).

The influence of Portuguese pidgin on the other Atlantic pidgins was effected through the slaves for whom the language had become a lingua franca as early as the fifteenth century (the vestiges of this Portuguese sub- or ad-stratum have been documented for several languages). This language made communication possible among the slaves and with their masters until another language was learned. When this second language was pidginized, it often was pidginized along the pattern of the earlier one. For this reason Loftman speaks of a "Caribbean creole" grammar, regardless of the Indo-European language superimposed on it. To account for the differences in vocabulary Stewart has proposed the theory of "relexification" (1963).

The origin of pidgin lingua francas are for the most part hidden behind the veil of history. In only brief sketches can the origin of some be described. The past of others perhaps is buried in obscure or unknown records awaiting the scholar.

More important than knowledge of the origin of these lingua francas, however, is that of their subsequent history. What is significant about their linguistic development, about their part in the lives of human beings? What then are some of the linguistic and sociological concomitants in their use?

\section{LINGUISTIC CHANGES}

All lingua francas undergo certain linguistic changes which in their extreme form are called pidginization. As the use of a natural language is taken up by people for whom it is only a second language, either in the same or in a different area, it suffers from linguistic interference which is common in all bilingual situations. The speakers of the first (or 
source, $S$ ) language receive the second (or target, $T$ ) through the grid of their $S$ language. If, for example, the $S$ language had no gender whereas the $T$ language did, one finds - as in the case of Hausa feminine - that one is lost. In the same way other features of the language are "reinterpreted".

This process might be called simplification, and it affects the grammatical structure as well. Many of the devices used for distinguishing various parts of sentences from one another and for showing the relationships between these constituent parts may be lost. In Ngbandi, a tone language with three levels of tone, the pronouns and verbs are intimately related in the aspectual system: different combinations of pronouns and verbs are used to mark aspect and tense. Tone is also used to derive nouns from verbs, and in other parts of the language varies considerably, but regularly, in the context of other tones. Practically all of this has been lost in Sango, the contact language derived from it. While three tones still persist in Sango, they function hardly at all to distinguish words or to mark grammatical usage (Samarin, 1963). Were it not for the fact that it is a lingua franca used almost exclusively by Africans, who already speak tone languages, the distinctive function of tone might be altogether lost.

What is lost in the morphology is to some degree compensated for in the syntax. Sango therefore uses periphrasis to mark aspect or time. One says fadé mbi goe "I shall go" (literally "now I go") and mbi goe awe "I went" (literally "I go is finished").

Lingua francas accompany - in fact, make possible - culture contact and acculturation. It is no wonder therefore that their vocabularies show dramatic changes. This happens when the natural language can no longer compete with other languages, either because it has moved into a different area or because non-native speakers predominate over the native speakers where the language is indigenous. Thus where Pidgin English is spoken one can usually describe an original situation where learners of English were not only of inferior status but also far more numerous than speakers of English (as in Jamaica, Le Page 1960). The second case might be illustrated by South African Fanagalo or even Town Bemba of Northern Rhodesia.

Lexical borrowing (using words from other languages) and innovations (by extending meanings of old words or forming new words with old stock) characterize the aforementioned changes. Notice, for example, the following French words which in Sango convey meanings somewhat different from the original ones (Taber 1964): ça va "to recover from an illness", commandement "authority", compagne "wife", depuis "for a long time", doucement "slowly", jusqu'à "for a while", quinine "pill, tablet". 
When lingua francas are learned under controlled circumstances (e.g., in a classroom), and where there is a recognized value in attaining the normative standard, such linguistic developments occur on a much smaller scale. Yet they are nonetheless revealed in "accepted" dialects of such standard languages as English spoken in West Africa, the Caribbean, or India. Because of their close approximation to the standard there is little doubt that they will be tolerated. Difficulties will arise only when literature produced in the newer dialect is read by speakers of the standard (to some extent this already happens in reading the works of some Indians).

\section{FATE OF LINGUA FRANCAS}

What is the future of the languages now spoken by peoples whose cultures are marginal to the prestigious one? With what degree of accuracy can one predict their life expectancy? Assuming an inevitable demise, to what task can they be assigned? Can they accomplish some legitimate goal satisfactorily? These are questions to which responsible government officials and other interested people, such as religious leaders, have addressed themselves. Several fact-finding investigations have already been initiated but their reports are too often filed away with other governmental or private documents. A few conferences have been held. UNESCO convened a meeting of linguists in 1951 to discuss the use of vernacular languages in education (UNESCO 1953). In 1951 there met at Kitwe, Northern Rhodesia, a significant All Africa Conference on Christian Literature and Audio-Visual Communication. In Africa in July 1962 at Brazzaville an international congress of specialists discussed the subject of multilingualism in Africa. One of the sections, for which seven papers were presented, dealt specifically with pidgins and creoles on that continent (CCTA 1962).

The problem which faces policy makers is fraught with complexities. In every instance they are concerned with welding a heterogeneous multilingual political state into a unified and harmonious nation. To accomplish this they should like to reduce the number of languages. They also want to introduce their countries into the stream of modern civilization. For this they need either a world language in which there already is an important literature, or a local language which must be "modernized". This latter is no mean task. It is difficult enough for Arabic, which had to step from the Middle Ages into the Twentieth Century. How much more difficult it is for an undeveloped lingua franca, such as Swahili.

In many of the emergent nations, the official language is actually a 
marginal language, little known and little used by the population. In Haiti, for example, only about ten per cent of the population can be said to have mastered the French language (see UNESCO 1951, p. 38); the rest of the population uses Haitian Creole. Sometimes there is a blindness to the real facts. People in the more prestigious strata have been known to deny the very existence of a pidgin language (like Jamaican Creole) or to claim that "everybody knows" the official language (like French in the Central African Republic). Policy makers must therefore avail themselves of the ever-growing body of literature on all relevant subjects in addition to initiating sociological and linguistic studies; only then can they hope to have established a sound basis for operation.

Linguistic research is necessary to determine the exact nature of the lingua franca. For example, how many different forms of Swahili are there? What are the means in the language to permit it to adapt itself to growing needs? Answers to such questions are being sought for Swahili under the aegis of the East African Swahili Committee (Kampala), but such bodies are rare.

Sociological research must accompany linguistic research to assure a more probable prognosis concerning the outcome of any policy with linguistic ramifications. There are only a few ethnolinguistic monographs in circulation, although several anthropologists are currently interested in related subjects. An inescapable aspect of language use is that it is more than a communication code; it serves, among other things, to mark ethnic identification and prestige.

Some of the most interesting developments are taking place in Africa, which in many respects offers itself as an experimental laboratory to the linguists. Nida (1955), has discussed the linguistic developments on the continent. In a more recent paper by Richardson (1957) (which should be read with Epstein 1959), the competition between several languages as lingua francas is clearly presented. Briefly, there is developing in Northern Rhodesia a form of the Bemba language, a veritable lingua franca, which is gaining ascendance over Nyanja and the two other lingua francas - English and Fanagalo. Five reasons are given: (1) The mine workers in the copperbelt are linguistically heterogeneous; (2) Although Fanagalo had been used as a lingua franca until the last war, its identification with the denigrating policies of the Europeans, many of whom used only this language with the Africans, has stigmatized it; (3) The use of English by Africans is opposed by most Europeans, who see in its use an attempt to raise the Africans' status (cf. the discouragement of the learning of German and Dutch in the former colonies of the Cameroon and Indonesia); (4) Nyanja is identified with the people whose language is the lingua franca of the Army and police; (5) Bemba is spoken indigenously by over 60 per cent of the labor force. 


\section{CONCLUSION}

Lingua francas have served tribal communities and vast empires from time immemorial when linguistic diversity prevented social and literary intercourse. Among them have been many drastically reconstituted languages (the pidgins) whose study is currently being undertaken in several quarters. Some dare to say that these are vanishing from the modern world (Whinnom 1956), but the ease with which Korean Bamboo English developed leads one to imagine the inevitability of pidgins in the world.

Historians might feel that all things point to "one world" where internationalism or an international federation or monolithic state would require a single lingua franca. An informed person cannot deny this possibility. But, short of a totalitarian system, the rise of such a language is beset with difficulties.

A true world lingua franca would have its advantages. But can one develop without a totalitarian state? Someone has said that Russian is grammatically too complex to serve as such a language; English, however, already meets many of the requirements. In any case, should there ever be an international lingua franca, on thing is almost certain: like all lingua francas before it, it will pass through a stage of pidginization.

\section{REFERENCES}

Alexandre, $\mathbf{P}$.

1962 "Aperçu Sommaire sur le Pidgin A70 du Cameroun", Colloque sur le Multilinguisme (CCTA), pp. 251-56.

Bloomfield, Leonard 1933 Language (New York).

CCTA (Commission de Coopération Technique en Afrique) 1962 Colloque sur le Multilinguisme (Brazzaville).

Epstein, A. L.

1959 "Linguistic Innovation and Culture on the Copperbelt, Northern Rhodesia". Southwestern Journal of Anthropology, 15, 235-53.

Ferguson, Charles A., Gode, Alexander, and Pitman, I. J.

n.d. "Interlingua and Intermedia", The Linguistic Reporter (The Center Goad, Harold for Applied Linguistics), Supplement Number 3 (Washington, D.C.).

1958 Language in History (London).

Greenberg, Joseph $\mathbf{H}$.

1963 The Languages of Africa (= Indiana University Research Center in Anthropology, Folklore, and Linguistics, Publication 25) (Bloomington).

Hall, Robert A., Jr.

1943 Melanesian Pidgin English (Baltimore). 
Hall, Robert A. Jr.

1962 "The Life Cycle of Pidgin Languages", Lingua, 11, 151-56.

Le Page, Robert B. and De Camp, David

1960 Jamaican Creole (London).

Loftman, Beryl B.

1953 "Creole Languages of the Caribbean Arca" (Columbia University M. A. thesis).

Lopes da Silva, Baltasar

1957 O Dialecto Crioulo de Cabo Verde (Lisbon).

Nida, Eugene A.

1955 "Tribal and Trade Languages", African Studies, 14, 155-58.

Pierson, Donald

1942 Negroes in Brazil (Chicago).

Richardson, Irvine

1961 "Some Observations on the Status of Town Bemba in Northern Rhodesia", African Language Studies II, pp. 25-36 (London).

Samarin, William J.

1963 A Grammar of Sango (Hartford).

Stewart, William A.

1963 "Relexification as a Factor in the Evolution of Creole Languages". Paper read at the Thirty-Eighth Annual Meeting of the Linguistic Society of America (Chicago).

Taber, Charles R.

1964 French Loanwords in Sango: A Statistical Analysis of Incidence (Hartford Studies in Linguistics) (Hartford).

Thai, Pham Xuan

1957 Frater: The Simplest International Language Ever Constructed (Saigon).

UNESCO

UNESCO

1951 The Haiti Pilot Project: First Phase $1947-1949$ (Paris).

1953 The Use of Vernacular Languages in Education (Paris).

Weinreich, Uriel

1953 Languages in Contact (New York).

Whinnom, Keith

1956 Spanish Contact Vernaculars in the Fhilippine Islands (Hong Kong).

From Study of the Role of Second Languages in Asia, Africa and Latin America, F. A. Rice, ed. (Washington, Center for Applied Linguistics of the Modern Language Association, 1962), pp. 54-64. Revised and expanded by the author. Reprinted by permission. 